\title{
Thermogravimetric and Kinetic Analyses of Oil Palm Empty Fruit Bunch (OPEFB) Pellets Using the Distributed Activation Energy Model
}

\author{
Bemgba Bevan Nyakuma, Arshad Ahmad, Anwar Johari and \\ Tuan Amran Tuan Abdullah \\ Centre for Hydrogen Energy Institute of Future Energy, \\ Chemical Engineering Department, Universiti Teknologi Malaysia, \\ 81110 Skudai, Johor, Malaysia \\ *Corresponding author: bbnyax1@gmail.com
}

Published online: 25 November 2016

To cite this article: Nyakuma, B. B. et al. (2016). Thermogravimetric and kinetic analyses of oil palm empty fruit bunch (OPEFB) Pellets using the distributed activation energy model. J. Phys. Sci., 27(3), 67-83, http://dx.doi.org/10.21315/jps2016.27.3.5

To link to this article: http://dx.doi.org/10.21315/jps2016.27.3.5

\begin{abstract}
The thermal degradation behaviour and decomposition kinetics of oil palm empty fruit bunch (OPEFB) pellets were investigated using a thermogravimetric analyser and the distributed activation energy model (DAEM). The OPEFB pellets were heated from $30^{\circ} \mathrm{C}$ to $1000^{\circ} \mathrm{C}$ at three different heating rates $\left(5,10,20^{\circ} \mathrm{C} \mathrm{min}{ }^{-1}\right)$ under a nitrogen atmosphere. The thermogravimetric-derivative thermogravimetric (TG-DTG) curves revealed that the non-isothermal decomposition of OPEFB pellets occurred in the following three stages: drying $\left(35^{\circ} \mathrm{C}-175^{\circ} \mathrm{C}\right)$, active pyrolysis $\left(200^{\circ} \mathrm{C}-370^{\circ} \mathrm{C}\right)$ and passive pyrolysis $\left(370^{\circ} \mathrm{C}-1000^{\circ} \mathrm{C}\right)$, which resulted in the loss of moisture, volatile matter and char, respectively. The distributed activation energy model was subsequently used to determine the apparent activation energies (E) and pre-exponential factors (A), which ranged from $37.89 \mathrm{~kJ} \mathrm{~mol}^{-1}$ to $234.05 \mathrm{~kJ} \mathrm{~mol}^{-1}$ and from $2.05 \times 10^{2} \mathrm{~min}^{-1}$ to $3.54 \times 10^{18}$ $\mathrm{min}^{-1}$, respectively, for conversions of $\alpha=0.05-0.70$ during the thermal degradation. The wide $E$ and $A$ distributions obtained from the kinetic analysis are attributed to the complex chemical reactions of pyrolysis. The kinetic analysis revealed the kinetic compensation effect (KCE), with the highest $E$ and $A$ values occurring in the range of $\alpha=0.2-0.4$. This result indicates that the active pyrolysis stage is the rate-determining step during the thermal decomposition of OPEFB pellets.
\end{abstract}

Keywords: Thermogravimetry, oil palm, empty fruit bunches, pellets, energy model 


\section{INTRODUCTION}

Utilising biomass resources from the oil palm industry is a potentially viable route to clean, renewable and sustainable biofuels in the future. ${ }^{1}$ Biomass resources can be converted to solid, liquid and gaseous fuels via thermal conversion processes such as gasification, combustion and pyrolysis. ${ }^{2}$ Biomass thermal conversion via pyrolysis is considered to be the most practical and efficient method due to its high fuel-to-feed ratio and fuel flexibility. ${ }^{3}$ However, this complex process requires comprehensive analyses to effectively and efficiently design, optimise and scale up suitable thermal energy conversion systems. ${ }^{4,5}$ Consequently, various thermal analysis techniques and mathematical models have been developed to investigate complex biomass conversion reactions. ${ }^{6}$

The most commonly used analytical technique for investigating the thermochemical reactions and decomposition kinetics of biomass pyrolysis is thermogravimetric analysis (TGA).$^{7-9}$ This precise technique is used to measure the mass loss of a sample as a function of the temperature at a controlled heating rate under a gas atmosphere. TGA experiments can be performed under both isothermal and non-isothermal conditions. Non-isothermal methoids are more common due to their high sensitivity to experimental noise and low susceptibility to mass loss errors. ${ }^{2,4}$ Furthermore, non-isothermal TGA requires fewer data points than isothermal TGA to investigate the solid-state decomposition kinetics of thermal conversion processes. ${ }^{10}$ In addition, isothermal TGA analysis suffers from mass errors that occur due to ramping to the desired temperature during the analysis. ${ }^{4}$ The thermal decomposition kinetics of algae, ${ }^{3}$ wood, ${ }^{11}$ orange waste ${ }^{12}$ and agricultural residues ${ }^{13-16}$ have been studied by non-isothermal TGA under inert conditions.

The mathematical constructs developed to estimate biomass decomposition kinetic parameters can be broadly classified into the following two methods: model-fitting and model-free. ${ }^{17}$ The kinetic analysis of biomass decomposition using model-fitting methods such as the Coats-Redfern and Freeman-Carroll methods can be problematic, especially when a single heating rate is employed. Applying these mathematical methods to non-isothermal data can result in substantial divergence and different kinetic parameter values for the same thermogravimetric curve. ${ }^{4,17}$

Model-free methods have been used to effectively address the problems associated with model-fitting methods. Furthermore, these methods do not require prior knowledge of the governing reaction model to estimate the kinetic parameters. ${ }^{17,18}$ Hence, biomass decomposition kinetic parameters can be 
determined as a function of conversion via an aptly termed isoconversional approach such as the distributed activation energy model (DAEM) developed by Vand. ${ }^{19}$ The DAEM model is commonly used to predict biomass devolatisation behaviour and decomposition kinetics under inert conditions. ${ }^{5,20,21}$ In this model, the devolatisation process is assumed to occur via a set of parallel, irreversible first-order reactions. Consequently, this model can be employed to investigate biomass pyrolysis kinetics using non-isothermal TGA data. However, one notable drawback of this model is that all the frequency factors are assumed to have the same value, which means the kinetic composition effect (KCE) is effectively neglected. ${ }^{21}$ Despite this problem, numerous studies have successfully used the DAEM model to obtain excellent fits of the pyrolysis kinetics of several biomass species. ${ }^{22-24}$

To date, the kinetic analysis of the pyrolytic decomposition of oil palm empty fruit bunch (OPEFB) pellets has not been reported in the literature, despite their enormous potential for clean energy and power generation in Malaysia. Therefore, this study aims to use non-isothermal thermogravimetry to investigate OPEFB pellet decomposition kinetics under an inert atmosphere at different heating rates using the DAEM. This study provides a clear understanding of the thermochemical degradation kinetics of OPEFB pellets by estimating the kinetic parameters and thus demonstrates their potential for use as a pyrolysis fuel.

\section{EXPERIMENTAL}

OPEFB pellets were procured from the Felda Semenchu oil palm mill in Johor, Malaysia. The pellets were pulverised in a high-speed crusher machine (Kimah Malaysia, model RT 20) and sieved to obtain particles of $<125 \mu \mathrm{m}$. To determine the $\mathrm{CHNS} / \mathrm{O}$ composition of the fuel, ultimate analysis was performed using a Vario Micro Cube ${ }^{\mathrm{TM}}$ elemental analyser. Proximate analysis was conducted using standard techniques for moisture (ASTM E871-82), volatile matter (ASTM E872-82), ash (ASTM E1755-01) and fixed carbon. All measurements were repeated three times to ensure the accuracy and repeatability of the method.

Thermal analysis of the powdered OPEFB pellets was performed in a Netzsch 209 F3 thermogravimetric analyser using high purity nitrogen $(99.9 \%$, flow rate $=50 \mathrm{ml} \mathrm{min}$ ) as the purge gas. For each run, only 8-10 $\mathrm{mg}$ of the sample were used to prevent any secondary vapour-solid reactions from occurring and to eliminate mass-heat transfer effects during the thermal analysis. The samples were heated in an aluminium crucible from $30^{\circ} \mathrm{C}$ to $1000^{\circ} \mathrm{C}$ at heating rates of 5 , 10 and $20^{\circ} \mathrm{C} \mathrm{min}{ }^{-1}$, which are characteristic conditions in fixed bed reactors. ${ }^{25,26}$ 
The thermal decomposition parameters, including the onset temperature $T_{i}$, peak decomposition temperature $T_{p}$, mass loss rate (MLR), burnout temperature $T_{f}$, and residual mass, were determined from the TG-DTG peaks using Proteus 6.1 thermal analysis software (Netzsch).

The decomposition kinetics of the OPEFB pellets were analysed using the DAEM. The DAEM was employed in this study because it was assumed that the non-isothermal pyrolytic decomposition of OPEFB pellets occurs via a set of irreversible first-order reactions. ${ }^{27}$ This model can be used to simulate the change in the overall conversion or the yield of a given component during a thermal conversion process. ${ }^{19}$ Therefore, the change in the volatile content during OPEFB pellet pyrolysis can be expressed as:

$$
1-\frac{V}{V_{\infty}}=\int \Phi(E, T) f(E) d E
$$

where $V$ is the total volatile content evolved at time $t, V_{\infty}$ is the effective volatile content of the fuel, $\Phi(E, T)$ describes the temperature-dependent activation energy $E, f(E)$ is the normalised activation energy distribution curve for the irreversible first-order reactions, and $A$ is the frequency factor corresponding to the activation energy $E$. The function $\Phi(\mathrm{E}, \mathrm{T})$, which describes fuel devolatisation at the heating rate $\beta$, can be expressed mathematically as: $:^{27,28}$

$$
\Phi(E, T)=\exp \left(-\frac{A}{\beta} \int_{T_{0}}^{T} e^{-E / R T} d T\right)
$$

This equation can be solved by using numerical estimation techniques and introducing a step function at $E=E_{s}$, where $E_{s}$ is the activation energy at a given temperature $T$ and constant heating rate $\beta$. Therefore, the function $\Phi(\mathrm{E}, \mathrm{T})$ in Equation 1 can be simplified to:

$$
1-\frac{V}{V_{\infty}}=\int_{E s}^{\infty} f(E) d E
$$

This condition is valid when the following relation holds for $E=E_{s}$ :

$$
E \text { at } \Phi(E, T)=0.58
$$


Consequently, Equation 4 is applicable for many combinations of $\beta$ and $f(E)$, and the expression for $A$ that corresponds to activation energy $E$ at heating rate $\beta$ can be written as:

$$
0.545 \frac{\beta E}{A R T^{2}}=e^{-E / R T}
$$

Thus, an approximate equation for $\Phi(E, T)$ is:

$$
\Phi(E, T) \cong \exp \left(\frac{A R T^{2}}{\beta E} e^{-E / R T}\right)
$$

This mathematical approximation can be used to model $i$ reactions occurring at temperature $T$ and constant heating rate $\beta$ as shown in Equation 7:

$$
\frac{d\left(V / V_{\infty}\right)}{d T} \cong \frac{d\left(V_{i} / V_{\infty}\right)}{d T}=\frac{A_{i}}{\beta} \exp \left(\frac{E_{i}}{R T}\right)\left(\frac{V_{i \infty}}{V_{\infty}}-\frac{V_{i}}{V_{\infty}}\right)
$$

Consequently, this approximation can be used to determine the overall reaction rates from the evolved and effective volatile contents $V_{i}$ and $V_{i \infty}$, respectively, for the $i$ th first-order reaction at temperature $T$. Integrating Equation 7 results in the following expression for the devolatisation rate at a constant heating rate:

$$
1-\frac{V_{i}}{V_{i \infty}}=\exp \left(-\frac{A_{i}}{\beta} \int_{T_{0}}^{T} \exp \left(\frac{E_{i}}{R T}\right)\right) \cong \exp \left(-\frac{A_{i} R T^{2}}{\beta E} e^{-E / R T}\right)
$$

After taking the natural logarithm of each side of the equation and rearranging it, Equation 8 becomes:

$$
\ln \left(\frac{\beta}{T^{2}}\right)=\ln \left(\frac{A R}{E}\right)-\ln \left[-\ln \left(1-\frac{V_{i}}{V_{i \infty}}\right)\right]-\left(\frac{E}{R T}\right)
$$

Using the relation $1-V_{i} / V_{i \infty}=\Phi(E, T)=0.58$, a simplified form of Equation 9 can be obtained, resulting in the linear relationship between the kinetic parameters $\beta$, $A, E$ and $T$ shown in Equation 10. For simplicity, the term 0.6075 can be set to zero (0), which corresponds to the assumption that $1-V_{i} / V_{i \infty}=\Phi(E, T)=e^{-1}$. 


$$
\ln \left(\frac{\beta}{T^{2}}\right)=\ln \left(\frac{A R}{E}\right)+0.6075-\frac{E}{R} \frac{1}{T}
$$

By fitting a linear curve to the $\ln \left(\beta / T^{2}\right)$ vs $(1 / T)$ plot, the activation energy $E$ and frequency factor $A$ can be determined from the slope and intercept, respectively, and the conversion (degree of degradation) $\alpha$ can then be calculated from the following relation in the DAEM model: ${ }^{9}$

$$
\alpha=\frac{m_{o}-m_{a}}{m_{o}-m_{f}}
$$

where $m_{o}, m_{a}$ and $m_{f}$ are the initial, actual and final masses of the sample obtained at heating rate $\beta$ and the corresponding temperature $T(\mathrm{~K})$ during the thermal analysis.

\section{RESULTS AND DISCUSSION}

\subsection{Ultimate and Proximate Analyses}

The ultimate and proximate analysis results for the OPEFB pellets are presented in Table 1. The analyses were performed to determine the fuel elemental composition and predict the fuel decomposition behaviour during the thermal analysis. The components are denoted as follows: $C$ - carbon, $H$ - hydrogen, $N$ - nitrogen, $S$ - sulphur, $O$ - oxygen, $M$ - moisture, $V M$ - volatile matter, $F C$ fixed carbon, $A$ - ash and $H H V$ - higher heating value $\left(\mathrm{MJ} \mathrm{kg}^{-1}\right)$.

Table 1: Ultimate and proximate analyses of the OPEFB pellets.

\begin{tabular}{cccccccccc}
\hline $\mathrm{C}$ & $\mathrm{H}$ & $\mathrm{N}$ & $\mathrm{S}$ & $\mathrm{O}$ & $\mathrm{M}$ & $\mathrm{VM}$ & $\mathrm{FC}$ & $\mathrm{A}$ & $\mathrm{HHV}$ \\
\hline 45.14 & 6.05 & 0.54 & 0.20 & 48.08 & 8.11 & 72.1 & 14.91 & 4.89 & 17.57 \\
\hline
\end{tabular}

The proximate analysis revealed a high volatile content $(>70 \mathrm{wt} \%)$ and low moisture $(<10 \mathrm{wt} \%)$, fixed carbon $(<20 \mathrm{wt} \%)$ and ash $(<5 \mathrm{wt} \%)$ contents. The heating value $\left(17.57 \mathrm{MJ} \mathrm{kg}^{-1}\right)$ of the OPEFB pellets is higher than that of OPEFB fibre, ${ }^{29-31}$ highlighting the effect of pelletisation on solid biomass fuel quality.

The low $N$ and $S$ contents indicate that small quantities of $\mathrm{NO}_{\mathrm{x}}$ and $\mathrm{SO}_{\mathrm{x}}$ pollutants are probably emitted during OPEFB pellet pyrolysis. Furthermore, the thermal conversion efficiency of OPEFB pellets should be relatively high due to 
their low moisture content, and reactor operational problems due to sintering, agglomeration and corrosion should be minimised by their low ash content. ${ }^{32}$

\subsection{Thermal Analysis}

Figure 1 shows the TG-DTG curves for the OPEFB pellets obtained at a heating rate of $20^{\circ} \mathrm{C} \mathrm{min}^{-1}$. The results indicate that three distinct mass losses corresponding to different decomposition stages, i.e., drying (I), active pyrolysis (II) and passive pyrolysis (III) stages, occurred during the thermal conversion process. ${ }^{33,34}$ The drying stage (I), which was observed between $35^{\circ} \mathrm{C}$ and $175^{\circ} \mathrm{C}$, involved the removal of light volatile compounds and water molecules bound by surface tension. The mass loss during drying was $8.0 \%$, which is in agreement with the moisture $(M)$ content measured by proximate analysis (Table 1 ).

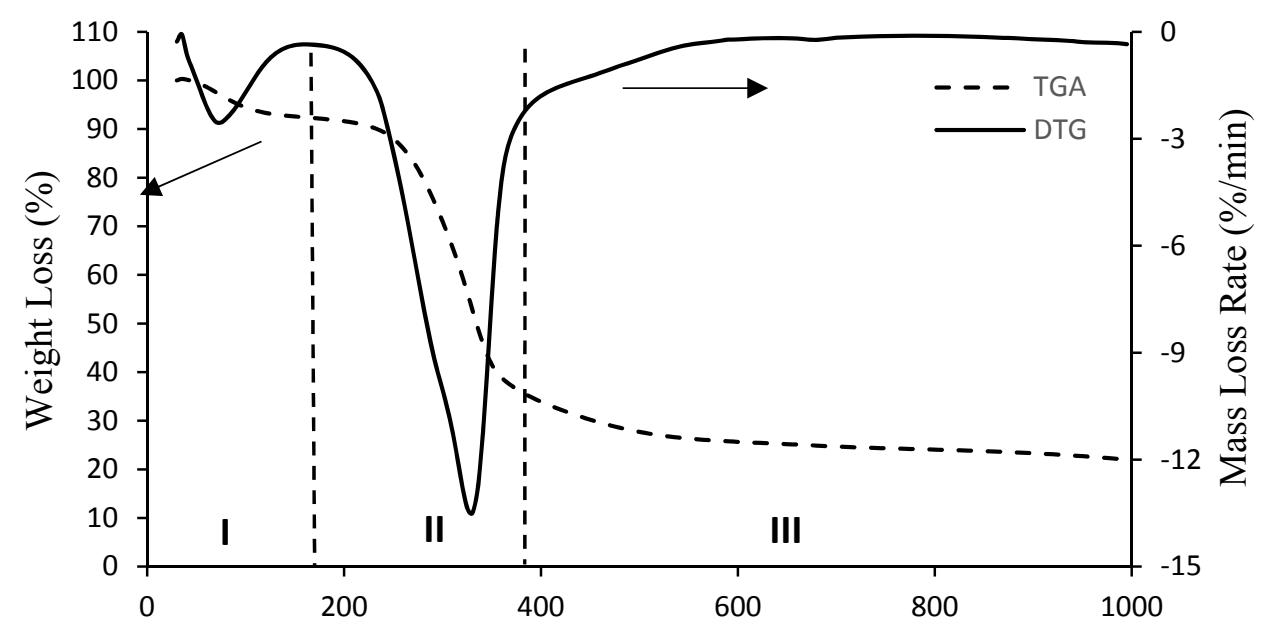

Temperature $\left({ }^{\circ} \mathrm{C}\right)$

Figure 1: TGA-DTG curves for the OPEFB pellets obtained at a heating rate of $20^{\circ} \mathrm{C} \min ^{-1}$.

A significant mass loss of $55 \%$ was observed during the active pyrolysis stage, which occurred between $200^{\circ} \mathrm{C}$ and $370^{\circ} \mathrm{C}$. According to Shafizadeh, ${ }^{35}$ the major components of lignocellulosic biomasses are hemicellulose, cellulose and lignin, which decompose in the temperature ranges of $160^{\circ} \mathrm{C}-360^{\circ} \mathrm{C}, 240^{\circ} \mathrm{C}-390^{\circ} \mathrm{C}$ and $180^{\circ} \mathrm{C}-900^{\circ} \mathrm{C}$, respectively. ${ }^{14}$ Therefore, during the active pyrolysis of OPEFB pellets in the temperature range of $200^{\circ} \mathrm{C}-70^{\circ} \mathrm{C}$, hemicellulose and cellulose (holocellulose) were degraded. Similarly, Yang et al. ${ }^{14}$ showed that palm kernel shell decomposes between $220^{\circ} \mathrm{C}$ and $340^{\circ} \mathrm{C}$ due to hemicellulose and cellulose 
degradation. The shoulder peak at $305^{\circ} \mathrm{C}$ was attributed to hemicellulose degradation. ${ }^{2,5}$ The holocellulose components constitute the volatile (liquid and gas) biomass pyrolysis products. ${ }^{36}$

The final stage (III) occurred between $370^{\circ} \mathrm{C}$ and $1000^{\circ} \mathrm{C}$ and resulted in a mass loss of $15.18 \%$, as indicated by the tailing observed in the TG-DTG curves. This stage is typically attributed to lignin decomposition, which occurs slowly over a broad temperature range of $180^{\circ} \mathrm{C}-900^{\circ} \mathrm{C}$ during thermal conversion. ${ }^{14,37}$ The slow lignin decomposition rate was due to the high lignin content, which resulted in char production as shown by a final residual char mass of $22.02 \%$ after thermal decomposition at a heating rate of $20^{\circ} \mathrm{C} \mathrm{min}^{-1}$.

\subsection{Effect of the Heating Rate on the Thermal Decomposition}

Table 2 shows the effects of the heating rate $\left(5,10\right.$ and $\left.20^{\circ} \mathrm{C} \mathrm{min}^{-1}\right)$ on the thermal characteristics, including the onset temperature $T_{i}$, peak decomposition temperature $T_{p}$, mass loss rate (MLR), and burnout temperature $T_{f}$, of the OPEFB pellets during active pyrolysis.

Table 2: Thermal characteristics of the OPEFB pellets during active pyrolysis.

\begin{tabular}{cccccc}
\hline $\begin{array}{c}\text { Heating } \\
\text { rate } \\
\left({ }^{\circ} \mathrm{C} \mathrm{min} \text { in }^{-1}\right)\end{array}$ & $\begin{array}{c}\text { Onset temp. } \\
\mathrm{T}_{i}\left({ }^{\circ} \mathrm{C}\right)\end{array}$ & $\begin{array}{c}\text { Peak temp. } \\
T_{p}\left({ }^{\circ} \mathrm{C}\right)\end{array}$ & $\begin{array}{c}\text { Mass loss } \\
\text { rate }(\mathrm{MLR}) \\
(\% / \mathrm{min})\end{array}$ & $\begin{array}{c}\text { Burnout } \\
\text { temp. } T_{f} \\
\left({ }^{\circ} \mathrm{C}\right)\end{array}$ & $\begin{array}{c}\text { Residual } \\
\text { weight } \\
(\%)\end{array}$ \\
\hline 5 & 257.40 & 308.30 & 4.05 & 339.40 & 11.03 \\
10 & 266.40 & 316.70 & 7.75 & 353.40 & 15.29 \\
20 & 273.30 & 329.60 & 13.84 & 370.70 & 22.02 \\
\hline
\end{tabular}

The fuel thermal characteristics MLR, $T_{i}, T_{p}$ and $T_{f}$ increased as the heating rate increased. The average MLR, $T_{i}, T_{p}$ and $T_{f}$ values were $8.55 \% \mathrm{~min}^{-1}, 265.70^{\circ} \mathrm{C}$, $318.20^{\circ} \mathrm{C}$ and $354.50^{\circ} \mathrm{C}$, respectively. The residual mass also increased from $11 \%$ to $22 \%$ as the heating rate was increased from $5^{\circ} \mathrm{C} \mathrm{min}{ }^{-1}$ to $20^{\circ} \mathrm{C} \mathrm{min}^{-1}$. In addition, the results show that the fuel pyrolysis was initiated at temperatures above $250^{\circ} \mathrm{C}$ and the onset temperature increased with increasing heating rate. Similar results were reported for oil palm shell, kernel and fibre wastes. ${ }^{16}$ The effects of the heating rate on the OPEFB pellet decomposition are revealed by the TG and DTG curves shown in Figures 2 and 3, respectively. 


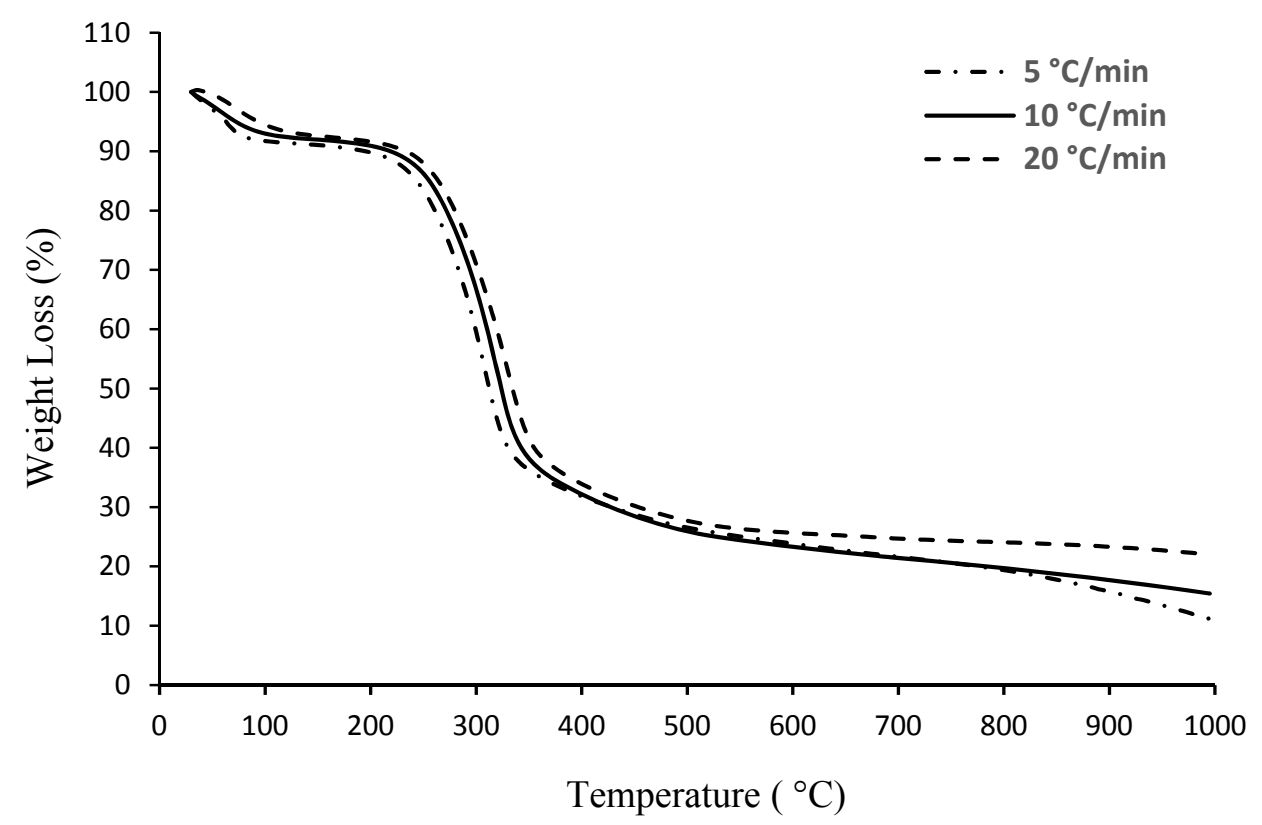

Figure 2: TG curves for the thermal decomposition of the OPEFB pellets.

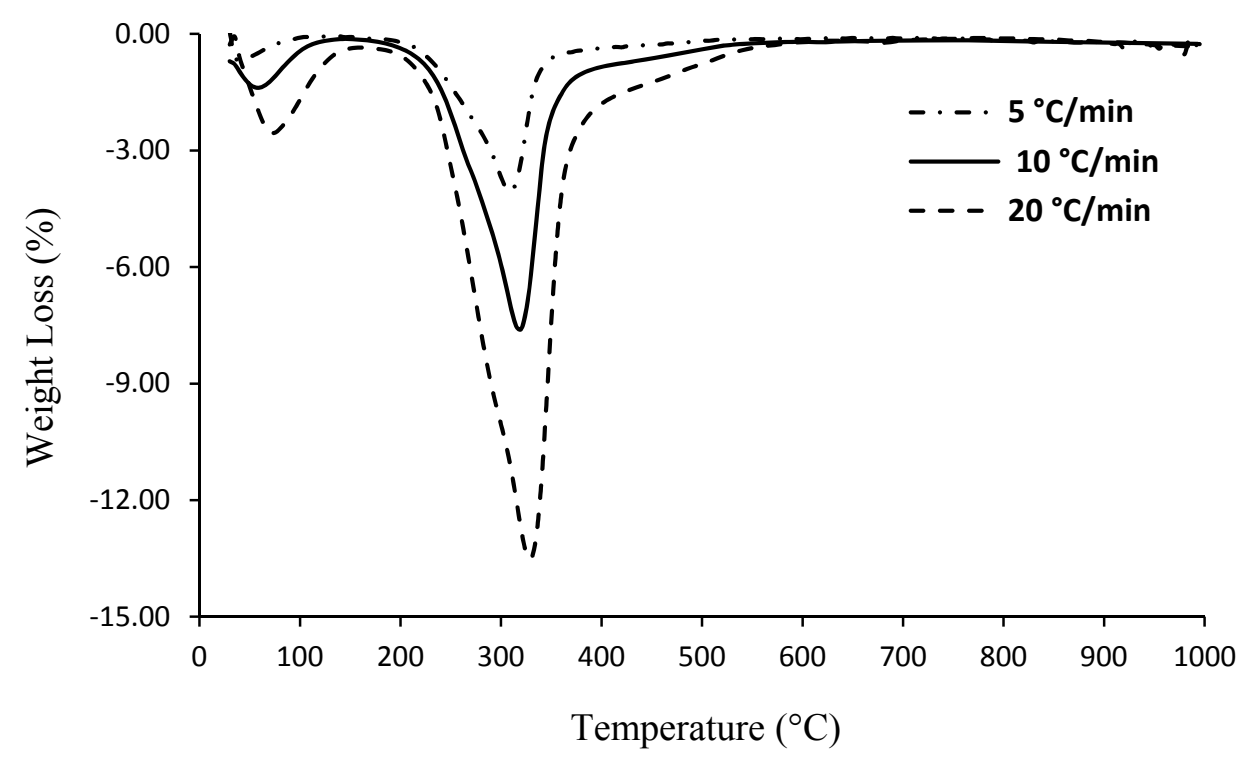

Figure 3: DTG curves for the thermal decomposition of the OPEFB pellets. 
Similarly, the TG-DTG curves shifted to the right (to higher temperatures) as the heating rate increased, due to a thermal delay caused by increasing the heating rate, which resulted in a decrease in the fuel degradation time during its pyrolytic decomposition. ${ }^{6}$ Generally, higher heating rates increase the heat transfer in the system and reduce the melted solid viscosity, thereby increasing the volatile yield during thermal analysis. Similar findings have been reported in the literature. ${ }^{38,39}$

Consequently, it can be concluded that the pyrolysis reaction temperature, heating rate and holocellulose and lignin reactivities are the most significant factors influencing biomass thermal degradation. Therefore, the pyrolysis product yield, composition and distribution can be optimised by altering these parameters.

\subsection{Kinetic Analysis}

The DAEM model was used to determine the kinetic parameters of OPEFB pellet decomposition. The kinetic parameters of thermal reactions significantly affect their reactivity and sensitivity. The activation energy $E$ is defined as the minimum amount of energy required for the reactants to react; therefore, higher $E$ values mean slower overall reaction rates. Figure 4 shows the regression plots used to estimate the kinetic parameters for fuel conversions of $\alpha=0.05-0.7$ at different heating rates. The correlation coefficients of all the plots were high with an average $R$ value of 0.9608 .

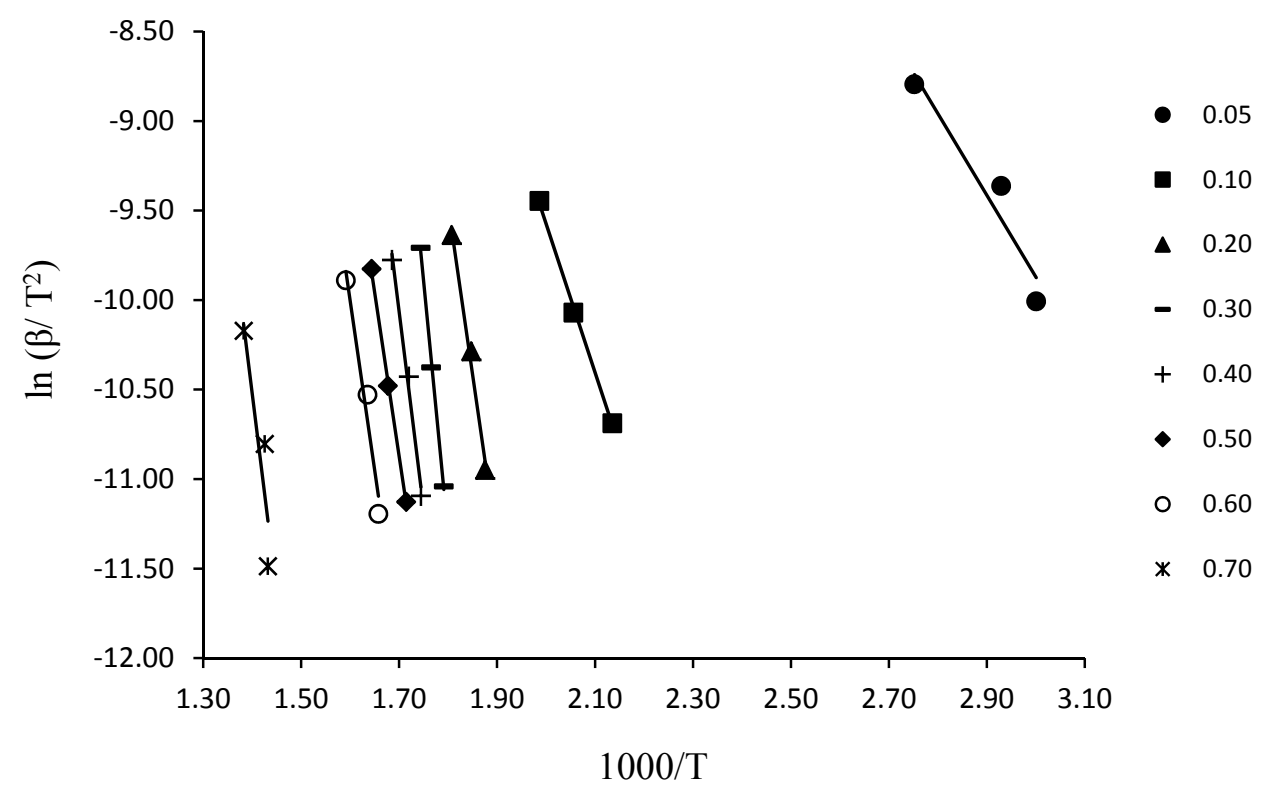

Figure 4: Regression lines for the OPEFB pellet decomposition kinetics. 
Using Equation 10, the apparent activation energies $(E)$ and frequency factors $(A)$ were calculated from the slopes and intercepts, respectively, of the linear curves fitted to the $\ln (\beta / T 2)$ against $(1 / T)$ plots. The plots in Figure 4 indicate that for different $V / V_{\infty}$, the volatile conversion during the fuel thermal decomposition can be described by a set of parallel first-order reactions. ${ }^{28}$ Furthermore, it can be inferred that the drying, active pyrolysis and passive pyrolysis stages of the thermal decomposition occurred in the $\alpha$ ranges of $0.05-0.10,0.20-0.60$ and $>0.70$, respectively. However, according to Aboyade et al. ${ }^{17}$ the calculated $E$ and $A$ values can only be referred to as "apparent values" because they account for the contributions of competing reactions to the overall reaction rate. The apparent activation energies $(E)$ and frequency factors $(A)$ for the fuel are presented in Table 3.

Table 3: Thermal Kinetic parameters of the OPEFB pellets.

\begin{tabular}{cccc}
\hline Conversion $(\alpha)$ & $E\left(\mathrm{~kJ} \mathrm{~mol}^{-1}\right)$ & $A\left(\mathrm{~min}^{-1}\right)$ & $R$ \\
\hline 0.05 & 37.89 & $2.05 \times 10^{02}$ & 0.9248 \\
0.10 & 69.17 & $9.75 \times 10^{03}$ & 0.9982 \\
0.20 & 158.33 & $1.14 \times 10^{12}$ & 0.9887 \\
0.30 & 234.05 & $3.54 \times 10^{18}$ & 0.9973 \\
0.40 & 183.19 & $1.74 \times 10^{13}$ & 0.9886 \\
0.50 & 152.69 & $1.26 \times 10^{10}$ & 0.9984 \\
0.60 & 157.42 & $1.23 \times 10^{10}$ & 0.9590 \\
0.70 & 183.86 & $1.66 \times 10^{10}$ & 0.8271 \\
\hline Average & 147.08 & $4.42 \times 10^{17}$ & 0.9603 \\
\hline
\end{tabular}

The average $E$ and $A$ values were $147.08 \mathrm{~kJ} \mathrm{~mol}^{-1}$ and $4.42 \times 10^{17} \mathrm{~min}^{-1}$, respectively. The apparent activation energy $(E)$ ranged from $37 \mathrm{~kJ} \mathrm{~mol}^{-1}$ to 234 $\mathrm{kJ} \mathrm{mol}^{-1}$, whereas the frequency factor ranged from $2.05 \times 10^{2} \mathrm{~min}^{-1}$ to $3.54 \times$ $10^{18} \mathrm{~min}^{-1}$. For comparison, the average $E$ values for selected biomasses determined using the DAEM model are presented in Table 4.

Table 4: Apparent activation energies of lignocellulosic biomasses.

\begin{tabular}{lcc}
\hline Biomass & Average $\mathrm{E}\left(\mathrm{kJ} \mathrm{mol}^{-1}\right)$ & Reference \\
\hline Cornstalk & $62-169$ & $17,23,35$ \\
Jerusalem artichoke & $146-232$ & 5 \\
Birch & $178-216$ & 20 \\
Lignin & $83-195$ & 36 \\
Wood pellets & $136-299$ & 37 \\
Ethiopian mustard & $167-232$ & 38 \\
\hline
\end{tabular}


The $E$ and $A$ values of the OPEFB pellets (Table 3) and other biomasses (Table 4) have wide distributions and fluctuate significantly in the kinetic analyses. These results can be attributed to the energy requirements of the complex chemical reactions that occur during thermal conversion. Furthermore, they highlight the effect of the conversion on the activation energy. ${ }^{9}$ Therefore, it can be inferred that the reaction rate of the drying stage $(\alpha=0.05-0.10)$, which had an activation energy in the range of $37.89-69.17 \mathrm{~kJ} \mathrm{~mol}^{-1}$, was faster than those of the active pyrolysis $(\alpha=0.20-0.60)$ and passive pyrolysis $(\alpha>0.80)$ stages.

\subsection{Kinetic Compensation Effect (KCE)}

Figure 5 shows the relationships between the conversion and the kinetic parameters $E$ and $A$. These relationships were found to be linear, demonstrating the kinetic compensation effect (KCE) in the thermal conversion of the OPEFB pellets. The KCE is the increase in the frequency factor $A$ that occurs to offset an increase in the activation energy $E$.

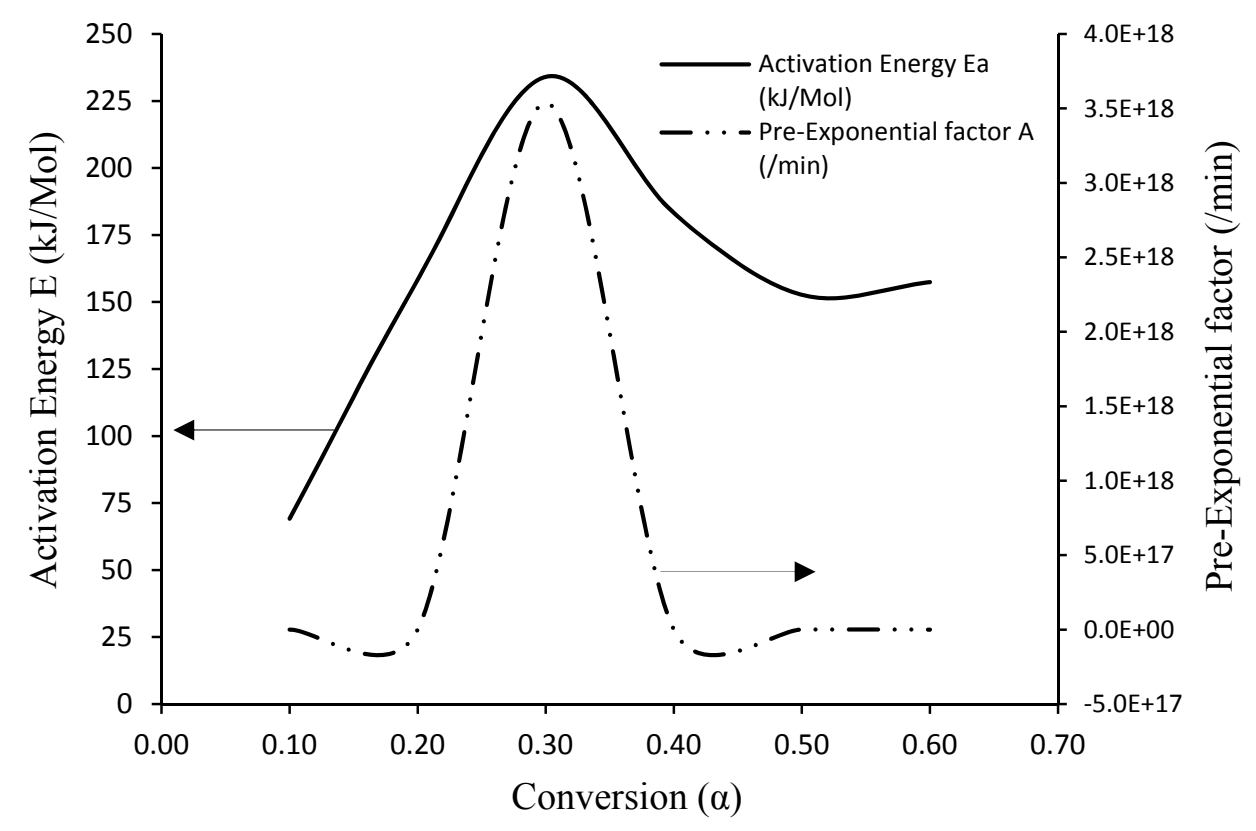

Figure 5: Kinetic compensation effect for the OPEFB pellets.

This phenomenon can also describe the OPEFB reactivity during the thermal decomposition process. Based on the activation energy definition, high $E$ values correspond to slow reaction rates. Therefore, at the OPEFB pellet conversion of $\alpha=0.3$, where $E=234.05 \mathrm{~kJ} \mathrm{~mol}^{-1}$ and $A=3.54 \times 10^{18} \mathrm{~min}^{-1}$, the thermal 
decomposition rate was the slowest, possibly due to the complex volatile and holocellulose degradation reactions that led to significant mass loss during the thermal analysis. This result is consistent with those of Sun et al., ${ }^{40}$ who found that the $E$ values for cellulose and hemicellulose degradation range from $100 \mathrm{~kJ}$ $\mathrm{mol}^{-1}$ to $200 \mathrm{~kJ} \mathrm{~mol}^{-1}$, and confirms that the rate-determining step is active pyrolysis.

\section{CONCLUSION}

In this study, a thermal analysis of OPEFB pellet decomposition under nitrogen flow and non-isothermal conditions was performed. The TG-DTG curves reveal that the OPEFB decomposition occurred in the following three distinct stages: drying, active pyrolysis and passive pyrolysis. Increasing the heating rate resulted in a significant lateral shift in the TG-DTG curves to higher temperatures. Similarly, the thermal parameters MLR, $T_{i}, T_{p}$ and $T_{f}$ increased with increasing heating rate. Furthermore, pyrolysis was initiated at temperatures above $250^{\circ} \mathrm{C}$ at all the heating rates studied, and the most significant mass loss (55\%) was observed during active pyrolysis. At a heating rate of $20^{\circ} \mathrm{C} \mathrm{min}^{-1}$, the mass losses during drying and passive pyrolysis were $8 \%$ and $15 \%$, respectively. The decomposition kinetics were analysed using the DAEM model to determine the activation energy $E$ and frequency factor $A$. The apparent activation energies $(E)$ were in the range of $37-234.05 \mathrm{~kJ} \mathrm{~mol}^{-1}$, and the frequency factors ranged from $2.05 \times 10^{2} \mathrm{~min}^{-1}$ to $3.54 \times 10^{18} \mathrm{~min}^{-1}$. The kinetic compensation effect was observed during the thermal analysis of the fuel. Based on the results, OPEFB pellets can be successfully used as a pyrolysis feedstock.

\section{ACKNOWLEDGMENT}

The authors acknowledge the financial support of the Malaysian Ministry of Higher Education through the Long Research Grant Scheme VOT No. 4L817 and the Universiti Teknologi Malaysia (UTM) Skudai, Johor Bahru, Malaysia. The contributions of S. L. Wong and M. F. A. Halim of ProCREST, Universiti Teknologi MARA (UiTM) Shah Alam are gratefully acknowledged. 


\section{REFERENCES}

1. Johari, A. et al. (2015). The challenges and prospects of palm oil based biodiesel in Malaysia. Energy, 81, 255-261, http://dx.doi.org/10.1016/ j.energy.2014.12.037.

2. Açikalin, K. (2011). Thermogravimetric analysis of walnut shell as pyrolysis feedstock. J. Therm. Anal. Calorim., 105(1), 145-150, http://dx.doi.org/10.1007/s10973-010-1267-x.

3. Shuping, Z. et al. (2010). Pyrolysis characteristics and kinetics of the marine microalgae Dunaliella tertiolecta using thermogravimetric analyzer. Biores. Technol., 101(1), 359-365, http://dx.doi.org/10.1016/ j.biortech.2009.08.020.

4. Gai, C., Dong, Y. \& Zhang, T. (2013). The kinetic analysis of the pyrolysis of agricultural residue under non-isothermal conditions. Biores. Technol., 127, 298-305, http://dx.doi.org/10.1016/j.biortech.2012.09.089.

5. Li, L. et al. (2013). Thermogravimetric and kinetic analysis of energy crop Jerusalem artichoke using the distributed activation energy model. $J$. Therm. Anal. Calorim., 114(3), 1183-1189, http://dx.doi.org/10.1007/ s10973-013-3115-2.

6. Damartzis, T. et al. (2011). Thermal degradation studies and kinetic modeling of cardoon (Cynara cardunculus) pyrolysis using thermogravimetric analysis (TGA). Biores. Technol., 102(10), 62306238, http://dx.doi.org/10.1016/j.biortech.2011.02.060.

7. Balogun, A. O., Lasode, O. A. \& McDonald, A. G. (2014). Devolatilisation kinetics and pyrolytic analyses of Tectona grandis (teak). Biores. Technol., 156, 57-62, http://dx.doi..org/10.1016/ j.biortech.2014.01.007.

8. Ceylan, S. \& Topcu, Y. (2014). Pyrolysis kinetics of hazelnut husk using thermogravimetric analysis. Biores. Technol., 156, 182-1888, http://dx.doi.org/10.1016/j.biortech.2014.01.040.

9. Slopiecka, K., Bartocci, P. \& Fantozzi, F. (2012). Thermogravimetric analysis and kinetic study of poplar wood pyrolysis. Appl. Energy, 97, 491-497, http://dx.doi.org/10.1016/j.apenergy.2011.12.056.

10. García-Ibañez, P., Sánchez, M. \& Cabanillas, A. (2006). Thermogravimetric analysis of olive-oil residue in air atmosphere. Fuel Process. Technol., 87(2), 103-107, http://dx.doi.org/10.1016/j.fuproc. 2005.08.005.

11. Poletto, M., Zattera, A. J. \& Santana, R. M. (2012). Thermal decomposition of wood: Kinetics and degradation mechanisms. Biores. Technol., 126, 7-12, http://dx.doi.org/10.1016/j.biortech.2012.08.133. 
12. Lopez-Velazquez, M. A. et al. (2013). Pyrolysis of orange waste: A thermo-kinetic study. J. Anal. Appl. Pyrol., 99, 170-177, http://dx.doi.org/10.1016/j.jaap.2012.09.016.

13. Guo, J. \& Lua, A. C. (2001). Kinetic study on pyrolytic process of oilpalm solid waste using two-step consecutive reaction model. Biomass Bioenergy, 20(3), 223-233, http://dx.doi.org/10.1016/S0961-9534(00) 00080-5.

14. Yang, H. et al. (2004). Thermogravimetric analysis-Fourier transform infrared analysis of palm oil waste pyrolysis. Energy Fuels, 18(6), 1814 1821, http://dx.doi.org/10.1021/ef030193m.

15. Biagini, E., Fantei, A. \& Tognotti, L. (2008). Effect of the heating rate on the devolatilization of biomass residues. Thermochim. Acta, 472(1-2), 55-63, http://dx.doi.org/10.1016/j.tca.2008.03.015.

16. Luangkiattikhun, P., Tangsathitkulchai, C. \& Tangsathitkulchai, M. (2008). Non-isothermal thermogravimetric analysis of oil-palm solid wastes. Biores. Technol., 99(5), 986-997, http://dx.doi.org/10.1016/ j.biortech.2007.03.001.

17. Aboyade, A. O. et al. (2011). Non-isothermal kinetic analysis of the devolatilization of corn cobs and sugar cane bagasse in an inert atmosphere. Thermochim. Acta, 517(1-2), 81-89, http://dx.doi.org/ 10.1016/j.tca.2011.01.035.

18. Vyazovkin, S. (2006). Model-free kinetics: Staying free of multiplying entities without necessity. J. Therm. Anal. Calorim., 83(1), 45-51, http://dx.doi.org/10.1007\%2Fs10973-005-7044-6.

19. Vladimir, V. (1943). A theory of the irreversible electrical resistance changes of metallic films evaporated in vacuum. Proceed. Phys. Soc., 55(3), 222-246, http://dx.doi.org/10.1088/0959-5309/55/3/308.

20. Shen, D. K. et al. (2011). Thermal degradation mechanisms of wood under inert and oxidative environments using DAEM methods. Biores. Technol., 102(2), 2047-2052, http://dx.doi.org/10.1016/j.biortech. 2010.09.081.

21. Hattingh, B. B. et al. (2014). Modeling the nonisothermal devolatilization kinetics of typical South African coals. Energy Fuels, 28(2), 920-933, http://dx.doi.org/10.1021/ef402124f.

22. Cai, J. \& Liu, R. (2008). New distributed activation energy model: numerical solution and application to pyrolysis kinetics of some types of biomass. Biores. Technol., 99(8), 2795-2799, http://dx.doi.org/ 10.1016/j.biortech.2007.06.033. 
23. Li, Z. et al. (2009). Analysis of coals and biomass pyrolysis using the distributed activation energy model. Biores. Technol., 100(2), 948-952, http://dx.doi.org/10.1016/j.biortech.2008.07.032.

24. Sonobe, T. \& Worasuwannarak, N. (2008). Kinetic analyses of biomass pyrolysis using the distributed activation energy model. Fuel, 87(3), 414-421, http://dx.doi.org/10.1016/j.fuel.2007.05.004.

25. Di Blasi, C. D., Signorelli, G. \& Portoricco, G. (1999). Countercurrent fixed-bed gasification of biomass at laboratory scale. Industr. Eng. Chem. Res., 38(7), 2571-2581, http://dx.doi.org/10.1021/ie980753i.

26. Nyakuma, B. B. et al. (2014). Gasification of empty fruit bunch briquettes in a fixed bed tubular reactor for hydrogen production. Appl. Mech. Mater., 699, 534-539, http://dx.doi.org/10.4028/www.scientific. net/AMM.699.534.

27. Miura, K. (1995). A new and simple method to estimate $\mathrm{f}(\mathrm{E})$ and $\mathrm{k} 0(\mathrm{E})$ in the distributed activation energy model from three sets of experimental data. Energy Fuels, 9(2), 302-307, http://dx.doi.org/10.1021/ef000 $50 \mathrm{a} 014$.

28. Miura, K. \& Maki, T. (1998). A simple method for estimating $\mathrm{f}(\mathrm{E})$ and k0(E) in the distributed activation energy model. Energy Fuels, 12(5), 864-869, http://dx.doi.org/10.1021/ef970212q.

29. Lahijani, P. \& Zainal, Z. A. (2011). Gasification of palm empty fruit bunch in a bubbling fluidized bed: A performance and agglomeration study. Biores. Technol., 102(2), 2068-2076, http://dx.doi.org/10.1016/ j.biortech.2010.09.101.

30. Mohammed, M. A. A. et al. (2012). Gasification of oil palm empty fruit bunches: A characterization and kinetic study. Biores. Technol., 110, 628-636, http://dx.doi.org/10.1016/j.biortech.2012.01.056.

31. Anissa, N. et al. (2015). Production of low-potassium solid fuel from empty fruit bunches (EFB) by employing hydrothermal treatment and water washing process. J. Jap. Inst. Energy, 94(1), 775-780, http://doi.org/10.3775/jie.94.775.

32. Baxter, L. L. (1993). Ash deposition during biomass and coal combustion: A mechanistic approach. Biomass Bioenergy, 4(2), 85-102, http://dx.doi.org/10.1016/0961-9534(93)90031-X.

33. Oladokun, O. et al. (2015). Modelling multicomponent devolatilization kinetics of Imperata cylindrica. Chem. Eng. Trans., 45, 919-924, http://dx.doi.org/10.3303/CET1545154.

34. Nyakuma, B. B. (2015). Thermogravimetric and kinetic analysis of melon (Citrullus colocynthis L.) seed husk using the distributed activation energy model. Environ. Climate Technol., 15(1), 77-89, http://dx.doi.org/10.1515/rtuect-2015-0007. 
35. Shafizadeh, F. (1982). Introduction to pyrolysis of biomass. J. Anal. Appl. Pyrol., 3(4), 283-305, http://dx.doi.org/10.1016/0165-2370(82) 80017-X.

36. Basu, P. (2010). Biomass gasification and pyrolysis: Practical design and theory. New York: Academic Press.

37. Souza, B., Moreira, A. \& Teixeira, A. F. (2009). TG-FTIR coupling to monitor the pyrolysis products from agricultural residues. J. Therm. Anal. Calorim., 97(2), 637-642, http://dx.doi.org/10.1007/s10973-009-0367-y.

38. Jeguirim, M. \& Trouvé, G. (2009). Pyrolysis characteristics and kinetics of Arundo donax using thermogravimetric analysis. Biores. Technol., 100(17), 4026-4031, http://dx.doi.org/10.1016/j.biortech.2009.03.033.

39. Vamvuka, D., Topouzi, V. \& Sfakiotakis, S. (2010). Evaluation of production yield and thermal processing of switchgrass as a bio-energy crop for the Mediterranean region. Fuel Process. Technol., 91(9), 988996, http://dx.doi.org/10.1016/j.fuproc.2010.02.018.

40. Sun, W. G. et al. (2012). The pyrolysis characteristics and kinetics of Jerusalem artichokestalk using thermogravimetric analysis. Energy Sources A, 34(7), 626-635. 